\title{
Found Different Attitude Fracture Characteristics of the NMR Curve by Application of 3D Printing Samples
}

\author{
Minggao Luo', Baoxin Chen², Maoshu Luo', Fenglai Yang², Nancy Song1, Binghui Song2 \\ ${ }^{1}$ College of Earth Science and Technology, Southwest Petroleum University, Chengdu, Sichuan \\ ${ }^{2}$ The Exploration and Development Research Institute, PetroChina Tarim Oilfield Company, Korla, Xinjiang \\ Email: luomg756@126.com
}

How to cite this paper: Luo, M.G., Chen, B.X., Luo, M.S., Yang, F.L., Song, N. and Song, B.H. (2017) Found Different Attitude Fracture Characteristics of the NMR Curve by Application of 3D Printing Samples. Journal of Geoscience and Environment Protection, 5, 223-230.

https://doi.org/10.4236/gep.2017.57017

Received: June 9, 2017

Accepted: July 25, 2017

Published: July 28, 2017

\begin{abstract}
Nuclear magnetic resonance (NMR) has many advantages, such as little testing time, no harm to rock specimen, and is widely used in the measurement of reservoir pore structure. 3D printing also has many advantages, such as repeating the printing the same attributes samples, forming sample by known rock pore structure, adding different pores or fractures to sample. For the study of fractured reservoir provides a new train of thought by combining NMR and 3D printing. Nuclear magnetic core analysis is an important work in the study of core, using a $\mathrm{T}_{2}$ spectrum at a certain echo time can also be found in the core fractures. The study, by CT scans to establish reservoir pore structure, based on the basic of adding different attitude fracture forming four fracture characteristics of rock sample, using 3D printing for solid sample, through the analysis of the nuclear magnetic resonance (NMR) of these sample, get the response characteristics of fracture characteristics on the $T_{2}$ curve, the quantitative calculation of fracture porosity of rock sample, the result accord with to establish the model of fracture porosity is very good. For the study of fractured oil and gas reservoir development the new field.
\end{abstract}

\section{Keywords}

3D Printing Technology, Nuclear Magnetic Resonance (NMR), $T_{2}$ Curve, Fracture Porosity

\section{Introduction}

The fracture is the important medium of the reservoir, not only the important reservoir space, but also the good flowing channel. The existence of fractures can greatly improve the flowing characteristics of reservoirs, greatly improve the 
flowing capacity of the fluid and increase permeability.

The existence of fractures will greatly improve the industrial value of petroleum reservoir formation and improve the development significance of petroleum reservoir formation. For dense petroleum reservoir formation, the existence of fractures, can change the nature of the reservoir, the conventional porosity reservoir, change of fracture porosity reservoirs, or porous fractured reservoir.

More fractured reservoir development in our country, the reserves committee regulations of the state, for calculation of reserves fracture porosity reservoirs, need to calculate the storage of the fracture and pore reserves, respectively.

Thus, fractures in the reservoir exploration and development, oil and gas reserves calculation and other aspects are very important, however, fracture research mainly use intuitive core observation, microscopic thin section observation, imaging logging, such as observation, field outcrop observation of fracture parameters of quantitative is qualitative, or semi-quantitative method, is not a direct quantitative determination method.

The mechanism of nuclear magnetic resonance shows that when the hydrogen nucleus does transverse relaxation in the pore, it has a collision effect with the pore wall. The collision process causes the energy loss of the hydrogen nucleus, which makes the hydrogen nucleus return from the high energy state to the low energy state, the lateral relaxation of the hydrogen nucleus. Pore size determines how much hydrogen in the process of nuclear collisions with the pore wall, the smaller the porosity, the hydrogen nuclei in the process of doing the transverse relaxation, the greater the collision probability between the pore wall [1]. Pore is smaller, the hydrogen nuclei of transverse relaxation rate is higher, said the nuclear magnetic resonance image signal is called a longitudinal relaxation time $T_{1}$ (ms) image and transverse relaxation time $\mathrm{T}_{2}(\mathrm{~ms}), \mathrm{T}_{1}$ image measurement, nuclear magnetic resonance core analysis measure $T_{2}$ images, usually with a $T_{2}$ image pulse sequence for different echo time series $T_{2}$ images, different echo time series $\mathrm{T}_{2}$ images is used to calculate the proton density image, according to obtain $\mathrm{T}_{2}$ images, the proton density images can get porosity, permeability, the reservoir physical information such as the percentage of movable fluid [2] [3] [4].

Many scholars have conducted many studies on application of nuclear magnetic resonance (NMR) technology work: Zhao Jie [5] to carry out the nuclear magnetic resonance (NMR) technology such as evaluation of pore structure research, based on the core nuclear magnetic resonance spectrum holes and the contrast of mercury intrusion pore size distribution, the permeability coefficient of transformation model is established and the ratio relationship; the fractal geometry expressions of the nuclear magnetic resonance $T_{2}$ values were deduced by the method of using the magnetic resonance $T_{2}$ spectrum to study the pore fractal structure of the reservoir[6]. Shi Q and Pan Y.S. [7] using nuclear magnetic resonance (NMR) imaging technology research of fissure structure of coal, the main crevasse of the coal sample is obtained and water flow in the coal sample fluid channel [8]. At present, it is widely used in the analysis of the core 
analysis [9] [10] [11], reservoir evaluation, oil layer flowing mechanism and logging and so on.

Visible, nuclear magnetic resonance (NMR) technology in the study of reservoir structure has been preliminary application, this paper, by using nuclear magnetic resonance $T_{2}$ curve to identify the different types of reservoir cores, and it can estimate the core fracture porosity.

\section{The Basic Method of Nuclear Magnetic Resonance Measurement}

After sample in $100 \%$ saturated with water, measure a $\mathrm{T}_{2}$ distribution, can be at different time and $\mathrm{T}_{2}$ signal intensity (amplitude) relational data, on the basis of these data, can be calculated curve of rock porosity and effective porosity values. Then, the sample after dehydration processing, under the condition of the given pressure, free water out sample, only bound water in the pore space, and then do the NMR measurements, get a $\mathrm{T}_{2}$ distribution and cumulative pore volume porosity curve and irreducible water value (expressed in MBVI). Based on these observations, to make a MBVI and longitudinal axis vertical parallel lines, find and $100 \%$ saturated cumulative porosity curve intersection, according to the intersection as a with the parallel to the horizontal axis vertical, and horizontal axis intersection corresponding $T_{2}$ values that determine the $T_{2}$ cutoff value.

Nuclear magnetic method: to determine the irreducible water saturation corresponding to the sample, nuclear magnetic resonance $T_{2}$ spectrum curve is equal to the $T_{2}$ spectrum of nuclear magnetic irreducible water saturation is less than the $T_{2 \text { cutoff }}$ value of $T_{2 c}$ immobile package under peak area and the ratio of the $T_{2}$ spectrum of unit area. The volume of water is equal to the volume of pore volume, which is the difference between the volume of pore volume and the volume of water. In actual data processing, the determination of the $\mathrm{T}_{2}$ cutoff value $\mathrm{T}_{2 \text { cutoff }}$ is the key.

\section{The Characteristic of the $\mathrm{T}_{2}$ Curve of Different Pore Types}

Different reservoir pore structure features in nuclear magnetic resonance $T_{2}$ curve is different, generally sandstone reservoir, pore structure characteristics of pore throat, characterized by bimodal characteristics, low-peak in $\mathrm{T}_{2}$ small location, high-peak in $\mathrm{T}_{2}$ large location (Figure 1).

When the reservoir is dense, it may be multi-peak, usually high peak at $T_{2}$, and low peak at $\mathrm{T}_{2}$, small pore more, large pore less (Figure 2).

\section{Using CT Scanning Techniques to form Digital Samples}

Based on high resolution computed tomography (CT) scanning technology, can get the sample of the high resolution scanning images, these images are digital processing, identify the pore features of each image segmentation to extract, obtain the reservoir pore structure plane characteristics, and through the threedimensional modeling of reservoir pore structure, reservoir pore structures of 3D model (Figure 3). 


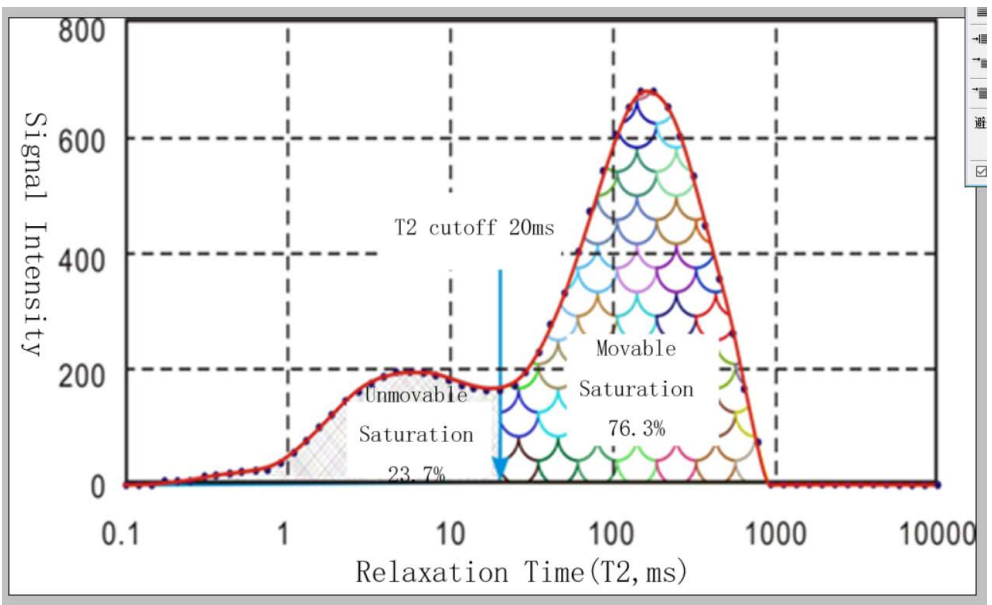

Figure 1. $\mathrm{NMR}_{2}$ curve for conventional reservoir formation.

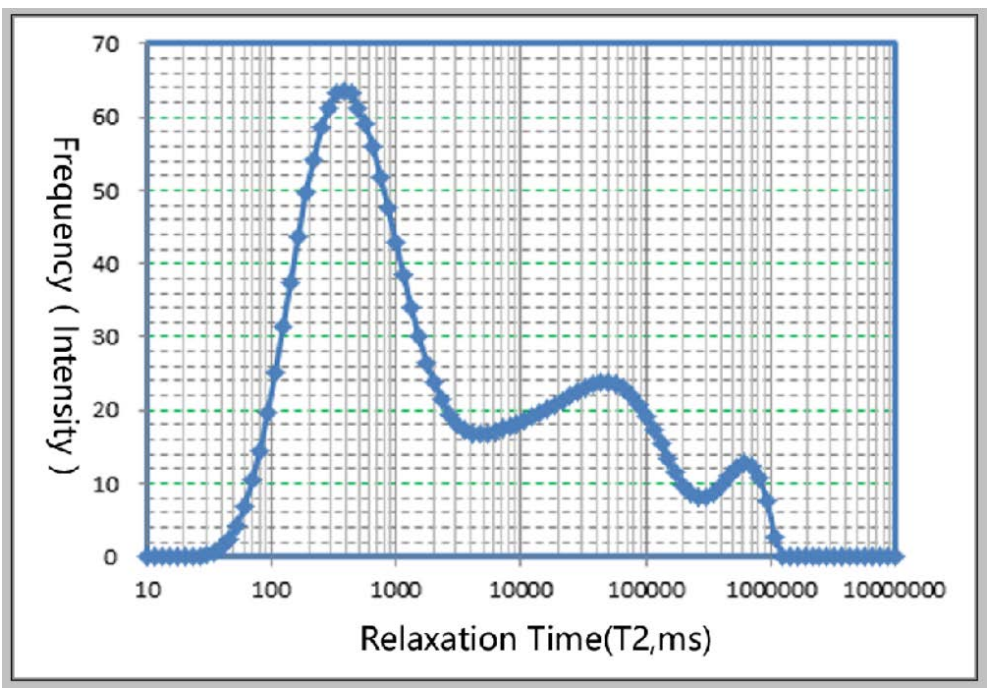

Figure 2. NMR $\mathrm{T}_{2}$ curve for tight reservoir formation.

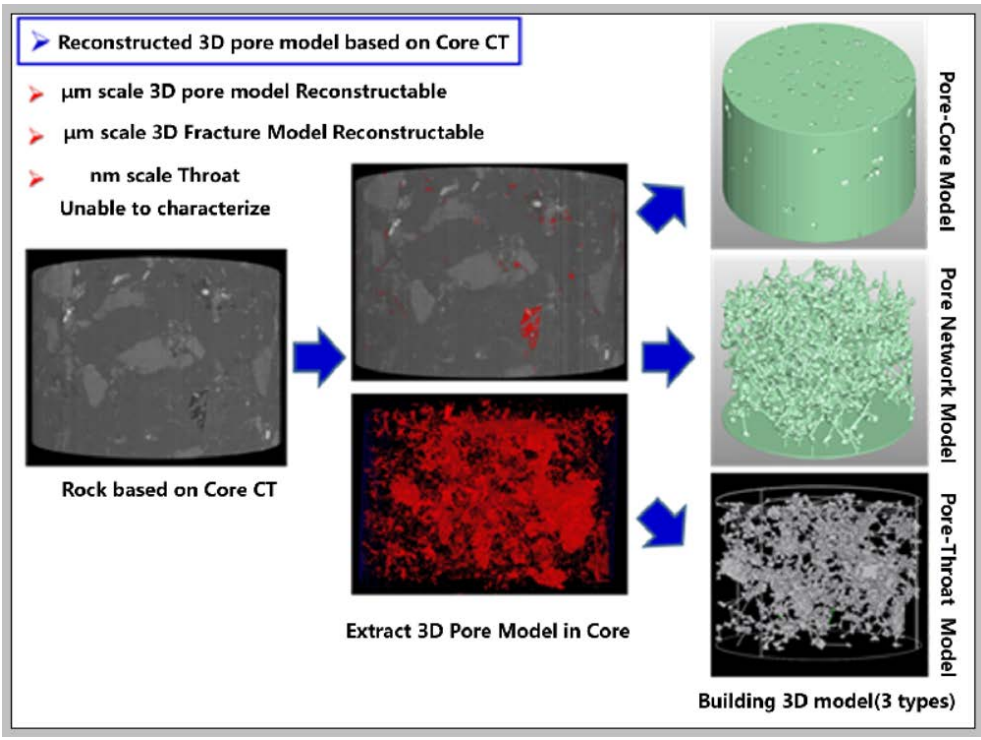

Figure 3. Establishing 3D pore structure model. 


\section{Use 3D Printing to Form Artificial Solid Rock Samples}

Form the sample after 3D pore structure model, through on the computer for further processing, can be formed with the same sample model of pore structure, this model can be in the high precision 3D printing machine printing (Figure 4).

The purpose of this study is to determine the fracture features of nuclear magnetic resonance (NMR) reaction, therefore, on the basis of rock pore structure, need 3D print out the fractures in the entity model of the sample. The feature of the nuclear magnetic resonance T2 curve is that the fractures are present in the reservoir. The second is whether there are different reactions of different characteristics of the fractures. Three is whether there is a different response to the continuity of the fracture.

Based on the above purposes, the four samples were designed: basic pore and single vertical fractures ( 2 \#); Basic porosity plus multiple intercostal fissures (3 \#); Basic porosity plus multiple discontinuities (4 \#); Basic pores add multiple discontinuities ( 5 ). The basic porosity of each rock is the same, the width of each rock fracture is the same. As shown in Figure 5.

\section{The Results of Different Production Fractures Were Compared}

The corresponding $T_{2}$ curves were obtained by using the magnetic resonance analysis of four samples of different yielding fractures, as shown in Figure 6. The $\mathrm{T}_{2}$ curve feature has the following characteristics:

1) The $T_{2}$ curve has three peaks, located at $1000 \mathrm{~ms}, 40,000 \mathrm{~ms}$, and 150,000 $\mathrm{ms}$;

2) The two low $T_{2}$ peaks are essentially the same, and the final high $T_{2}$ peaks are different;

3) 2 \# sample peak maximum, 5 \# sample peak lowest;

4) 2 \# is closer to 3 \#. 4 \# and 5 \# are closer.

Above all, in-situ fracture on $\mathrm{T}_{2}$ curve has obvious characteristics. The width of the fracture determines the peak $\mathrm{T}_{2}$ position. The volume of the fracture de-
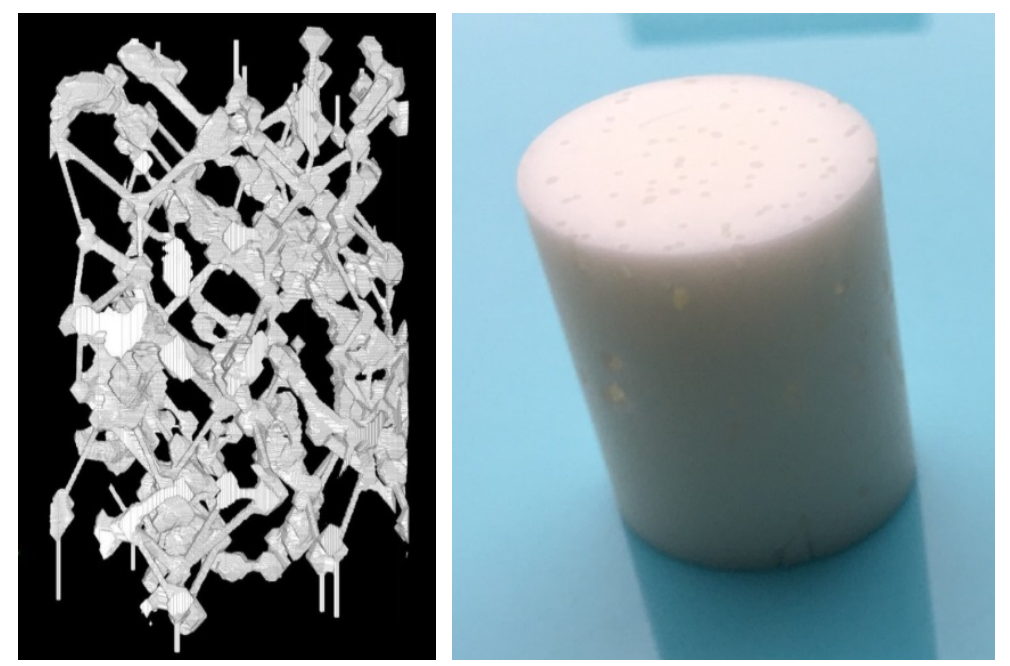

Figure 4. Entity model by 3D printing. 

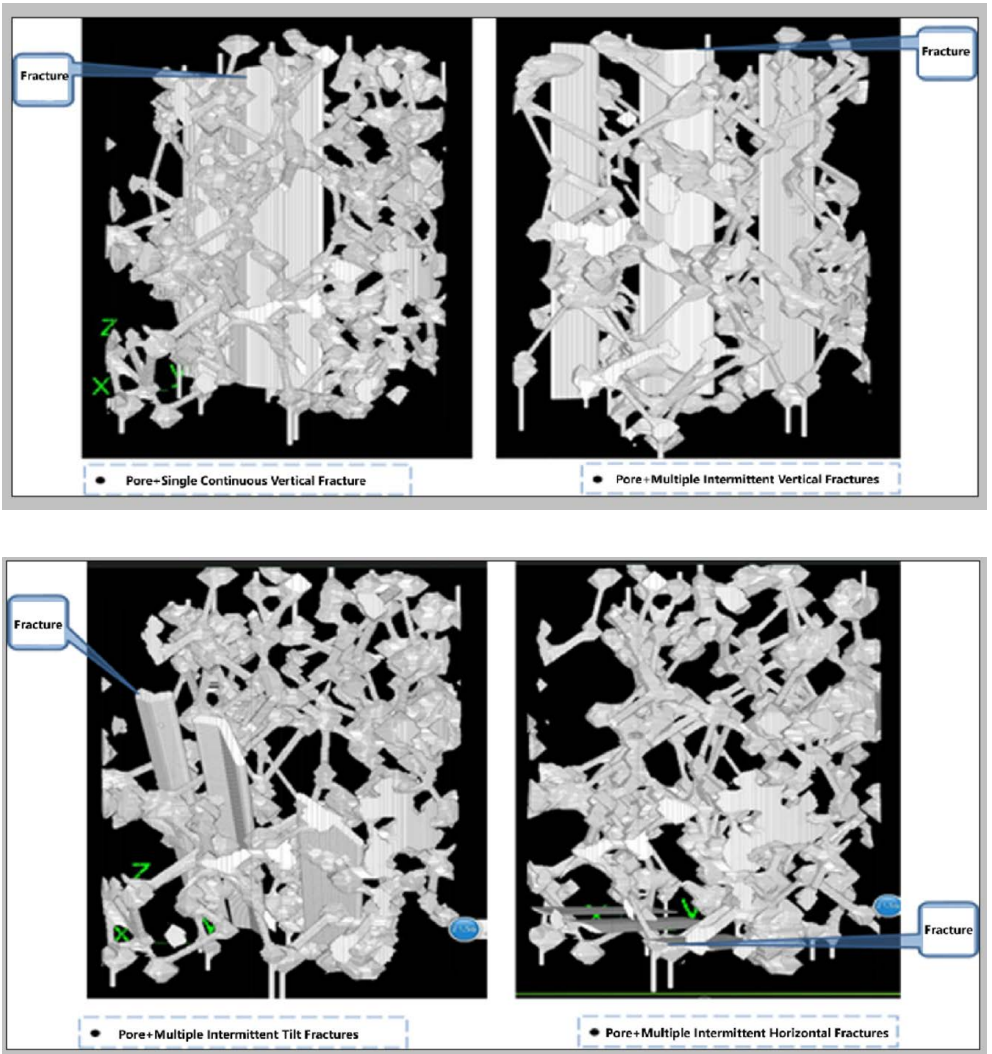

Figure 5. Four different attitude fracture models.

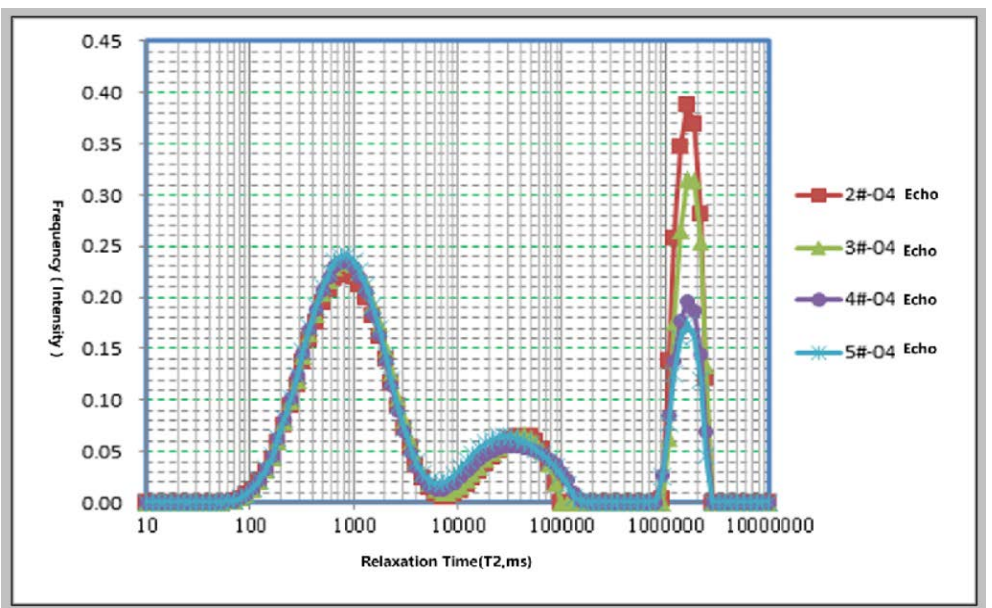

Figure 6. $\mathrm{T}_{2}$ curves for four different attitude fracture models.

termines the size of the peak (height). The $\mathrm{T}_{2}$ curve shows the width of the fracture, it has nothing to do with the production of the fracture. The $\mathrm{T}_{2}$ curve can reflect the total volume of the fracture, it has nothing to do with the continuity of the fracture.

\section{Fracture Porosity Calculation}

Based on the total porosity of the $\mathrm{T}_{2}$ curve, fracture porosity can be calculated quantitatively. Fracture in the reaction of the wave is calculated, by nuclear 
magnetic porosity calculation conversion, can obtain the total porosity curve, on this curve, fracture wave of start and end time $\mathrm{T}_{2}$ corresponding porosity difference is the fracture porosity. As shown in Figure 7, the cumulative porosity at the beginning of the fissure wave was $4.23 \%$; at the end of $6.14 \%$, and $1.91 \%$ of the increase was the fracture porosity of the core. The results show that the fracture porosity of the rock core is consistent with the design of the core of the core, indicating that the porosity is reliable.

Figure 8 is a tight sandstone gas reservoir 24\#, 205 Well, nuclear magnetic resonance $T_{2}$ sample curve characteristics. The existence of the sample fracture can be observed, through calculation, the fracture porosity of $0.24 \%$.

\section{Conclusions}

Through the use of 3D printing, simulation of different attitude fracture of the reservoir rock, forming different $3 \mathrm{D}$ printing sample, the application of nuclear magnetic resonance (NMR) test method, accurate to obtain the response cha-

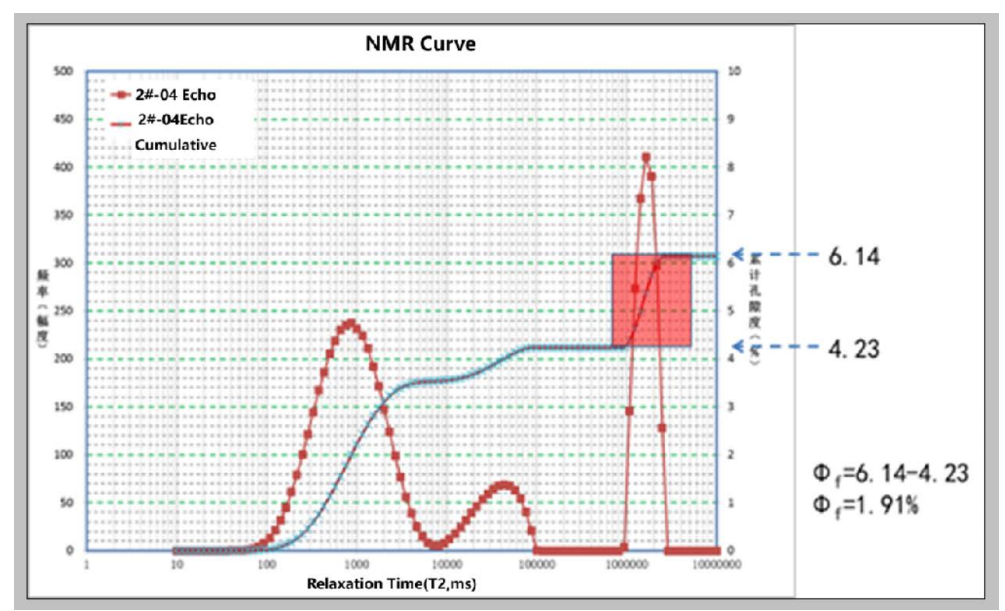

Figure 7. Schematic diagram of fracture porosity calculation for $2 \# 3 \mathrm{D}$ printing sample.

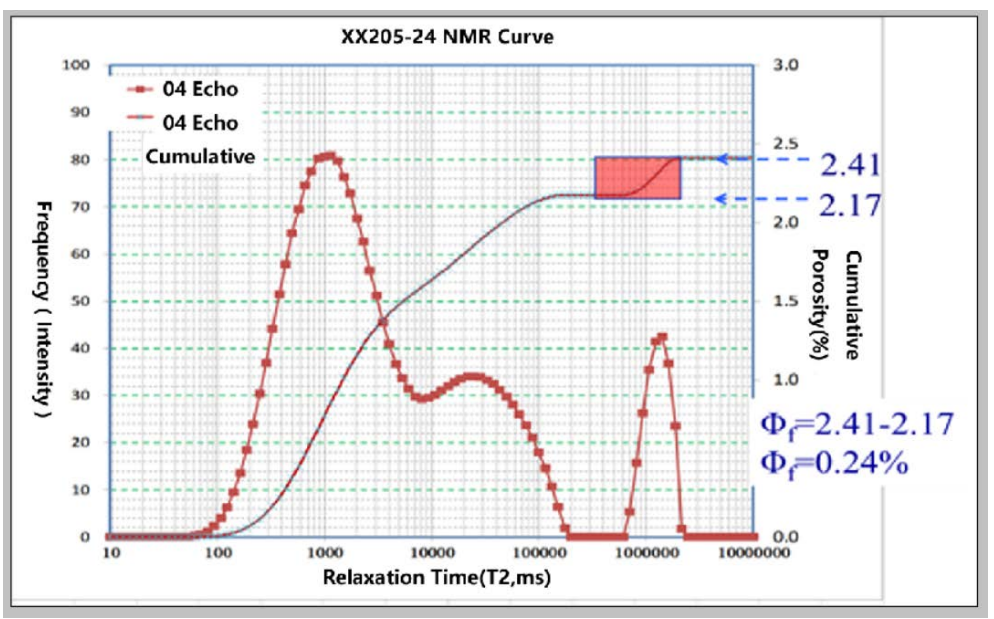

Figure 8. Schematic diagram of fracture porosity calculation for 24\# sample of XX205 well. 
racteristics of the fractures on the T2 curve, for fracture (fracture pore type and pore fracture, fracture) reservoir research provides a new method, also for the accurate calculation of fracture porosity, provides a simple and effective method. The main ideas are as follows:

1) The fissure in the rock sample, in the NMR T2 curve, has obvious response characteristics, which is the high amplitude of the narrow band, which is the unique response characteristic of the fissure.

2) The characteristic of the fracture, which is closely related to the width and volume of the fracture, is not related to the attitude of the fracture, and is not closely related to the continuity of the fracture.

3) The fracture porosity can be $T_{2}$ curve and nuclear magnetic porosity quantitative calculation, if the fracture characteristics and differences, pores in reservoir rocks in $T_{2}$ curve peak for independence, can use $T_{2}$ curve and the imaging porosity calculation to obtain;

4) 3D printing technology in various fields has a very wide range of application, the application in fractured reservoir analysis is a beneficial attempt, believe that applied in the study of oil and gas reservoirs have more broad prospects.

\section{References}

[1] Liu, T.Y., Wang, S.M., Fu, R.S., Zhou, M.S., Li, Y.H. and Luo, M. (2003) Nuclear Magnetic Resonance Spectroscopy of Rock Pore Throat Structure Analysis. Petroleum Geophysical Prospecting, 38, 328-333.

[2] Lang, D.J., Lv, C.Y., Lun, Z.M., Shang, G.H. and Pan, W.Y. (2012) Study of Method in Core Analysis by NMRI. CT Theory and Applications, 21, 27-35.

[3] Mendelsou, S.K. (1991) Magnetic Relaxation in Porous Media. Magnetic Resonance Imaging, 9, 651-655.

[4] Straley, C., Rossini, D., Vinegar, H., el al. (1994) Core Analysis by Low Field NMR. SCA Conference Paper 9404.

[5] Zhao, J., Jiang, Y.Z., Wang, W.N., Dong, M.S. (2003) Investigation of Rock Pore Structure Using NMR Technology. Well Logging Technology, 27, 185-188. (In Chinese)

[6] Zhang, C.M., Chen, Z.B., Zhang, Z.S., Li, J., Ling, H.S. and Sun, B.D. (2007) Fractal Characteristics of Reservoir Rock Pore Structure Based on NMR T2 Distribution. Journal of Oil and Gas Technology, 29, 80-86. (In Chinese)

[7] Shi, Q. and Pan, Y.S. (2005) A Method of Nuclear Magnetic Resonance Imaging Analyzed in the Crack and Fluid Pass Way of Coal Body. Coal Mining Technology, 10, 6-9. (In Chinese)

[8] Li, J.L., Zhou, K.P., Zhang, Y.M. and Xu, Y.J. (2012) Experimental Study on Freezing and Thawing Damage of Rock Pore Structure Based on Nuclear Magnetic Resonance. Chinese Journal of Rock Mechanics and Engineering, 31, 1208-1214.

[9] Liu, W., et al. (1998) Using NMR Technology to Determine the Movable Fluid Index of Rock Matrix in Xiaoguai Oil-Field. SPE 50903.

[10] Borjia, G.C., Bortolotti, V., Brancolini, A., et al. (1996) Developments Incore Analysis by NMR Measurements. Magnet Resonance Imaging, 14, 751-760.

[11] Timur, A. (1969) Pulsed Nuclear Magnetic Resonance Studies of Porosity, Movable Fluid, and Permeability of Sandstones. Journal of Petroleum Technology, 21, 775786. 
Submit or recommend next manuscript to SCIRP and we will provide best service for you:

Accepting pre-submission inquiries through Email, Facebook, LinkedIn, Twitter, etc. A wide selection of journals (inclusive of 9 subjects, more than 200 journals)

Providing 24-hour high-quality service

User-friendly online submission system

Fair and swift peer-review system

Efficient typesetting and proofreading procedure

Display of the result of downloads and visits, as well as the number of cited articles Maximum dissemination of your research work

Submit your manuscript at: http://papersubmission.scirp.org/

Or contact gep@scirp.org 